\title{
The functional status of neutrophils in patients with bronchial asthma, chronic obstructive pulmonary disease, bronchial asthma with chronic obstructive pulmonary disease, and community-acquired pneumonia
}

\begin{abstract}
Objective
To study the functional state of neutrophils in patients with bronchial asthma, bronchial asthma + COPD, COPD and community-acquired pneumonia to expand diagnosis, to determine the individual characteristics of the patients of the studied groups and choose the optimal methods of treatment.
\end{abstract}

\section{Abstract}

The study examined 217 people, including 78 patients with BA, 38 patients with COPD, 39 patients with $\mathrm{BA}+\mathrm{COPD}$, and 17 patients with CAP. The control group consisted of 25 patients with hypertension (HT) and ischemic heart disease (IHD) and 20 practically healthy people. All patients underwent studies of NE, AAT, phagocytic activity of neutrophils (PAN), respiratory burst (RB), pulmonary function and FeNO. The presence of IgE and IgG to Strept. pneumoniae, Neisseria perflava and Haemofil. influenzae and Staph. aureus in the blood serum was also measured. The parameters the characterize the functional status of neutrophils reflect the degree and significance of the inflammatory process in the bronchopulmonary system. Patients with BA+COPD have infective (bacterial) inflammation, demonstrated by bronchial obstruction and marked AAT, which was absent in patients with only BA or only COPD, which allows us to consider the combination of BA and COPD as a separate pathological condition.

Keywords: bronchial asthma, chronic obstructive pulmonary disease, neutrophils, neutrophil elastase, $\alpha 1$-antitrypsin, phagocytic activity of neutrophils, respiratory burst, fractional exhaled nitric oxide
Volume 5 Issue 2 - 2018

\section{Fedoseev GB, Trofimov VI, Negrutsa KV, Timchik VG, Golubeva VI,Aleksandrin VA, Razumovskaya TS}

Department of Inpatient Therapy, First Pavlov State Medical University of St. Petersburg, Russia

Correspondence: Fedoseev GB, Department of Inpatient Therapy, First Pavlov State Medical University of St. Petersburg, ul. L. Tolstogo 6/8, 197022 St. Petersburg, Russia, Emailfedoseevsp@mail.ru

Received: January 09, 2018 | Published: March 09, 2018
Abbreviations: BA, bronchial asthma; COPD, chronic obstructive pulmonary disease; NP, neutrophils; NE, neutrophil elastase; AAT, $\alpha 1$-antitrypsin; PAN, phagocytic activity of neutrophils; $\mathrm{RB}$, respiratory burst; FeNO, fractional exhaled nitric oxide

\section{Introduction}

Bronchial asthma (BA), chronic obstructive pulmonary disease (COPD), $\mathrm{BA}+\mathrm{COPD}$, and community-acquired pneumonia (CAP) are very common conditions. The main pathogenetic mechanism in the abovementioned conditions is inflammation, which is heterogeneous in both its etiology and pathogenesis in patients with these disorders. ${ }^{1}$ Neutrophils ensure and support body homeostasis and play a pivotal role in the defense against infections. ${ }^{2,3}$ One of the main causes of a chronic inflammatory process can be neutrophil dysfunction. Reacting to the various pathogenetic factors, neutrophils release active oxygen metabolites, proteolytic enzymes, etc. into the surrounding environment, thus 'cleaning up' the inflammatory site but concurrently destroying its own tissues.

The neutrophil phenotype of BA is associated with significant tissue destruction, the development of airway obstruction, a poor response to corticosteroids (CS), and consequently, a disease that is difficult to treat. ${ }^{4,5}$ The neutrophil component of inflammation in severe asthma is evidenced by increased elastase activity, which may be responsible for some elements of remodeling seen in severe BA. The reduction in lung tissue elasticity observed in severe BA may be related to an imbalance between oxidants and antioxidants and between proteolysis and antiproteolysis, which is accompanied by increased neutrophil elastase (NE) activity and is also seen in COPD and $\mathrm{CAP}^{6}{ }^{6} \mathrm{NE}$ is an inflammatory regulator, moreover, in different situations; NE can act as a pro-inflammatory and an anti-inflammatory agent. NE inactivation is primarily performed by $\alpha 1$-antitrypsin (AAT). ${ }^{7}$ The role of AAT is to prevent damage to lung parenchyma caused by proteases and to inhibit their excess production, to prevent pulmonary fibrosis, emphysema, bronchial and vascular remodeling and lung tissue destruction, and to suppress an excessive inflammatory response. $^{8}$

Neutrophils achieve their effector goals using phagocytosis, by releasing bactericidal products, which consist of granular contents containing biologically active substances. ${ }^{9,10}$ The phagocytosis targets are usually bacterial and fungal pathogens, protozoa and the body's own damaged cells. Children with poorly controlled asthma demonstrate a $50 \%$ reduction in phagocytosis by alveolar macrophages as compared to normal subjects. ${ }^{11,12} \mathrm{~A}$ disturbance in the ability to phagocytose Staph. aureus was identified in children with severe asthma. ${ }^{11}$ A reduced ability of alveolar macrophages to phagocytose bacteria in 
adults with severe asthma led to bacterial persistence and reduced treatment efficacy. ${ }^{13}$ A twofold reduction in alveolar macrophage phagocytosis in patients with severe asthma ${ }^{14}$ has been demonstrated, which was accompanied by alveolar macrophage apoptosis. ${ }^{15}$ Alveolar macrophage phagocytosis dysfunction in patients with asthma, COPD, and cystic fibrosis leads to bacterial colonization of the airways. ${ }^{16} \mathrm{All}$ this encourages bacterial colonization and worsening lung function. ${ }^{17}$ The number of alveolar macrophages in the lungs was 20 times higher in patients with COPD as compared to normal, ${ }^{18}$ and the abundance of neutrophils in the airways is one of the main characteristics of COPD. ${ }^{19}$ One of the reasons for the decreased phagocytic activity of neutrophils is the negative effect of NE on CR1 receptors on the neutrophil surface..$^{20}$ A positive correlation was established between airway obstruction measured by $\mathrm{FEV}_{1}$ and the reduction in bacterial phagocytosis by alveolar macrophages..$^{21}$ Microorganisms captured by phagocytes are killed through two microbicidal systems, the oxygendependent one, and the oxygen-independent one. ${ }^{22}$ The oxygendependent microbicidal mechanisms are related to the respiratory burst, which is characterized by increased oxygen consumption and is accompanied by an uptake of NADP with a concurrent release of biologically active products that have significant microbicidal properties. ${ }^{22}$ Active oxygen forms can irrevocably damage DNA, RNA, proteins, and lipids, which leads to biomembrane damage and dysfunction, and the destruction of various cells and tissues. ${ }^{23}$ Oxidant and antioxidant imbalance in patients with COPD creates oxidative stress, which is one of the pathogenetic mechanisms of COPD. ${ }^{24}$ The respiratory burst produced by alveolar macrophages may be reduced in patients with $\mathrm{BA}$, which worsens the phagocytic activity of macrophages, disrupts antimicrobial defense, ${ }^{25}$ leads to airway hypersensitivity and increased bronchial smooth muscle contractility, and increases mucus secretion.

Oxygen-independent mechanisms are activated during phagosome and lysosome fusion and are mediated by cationic proteins and hydrolytic enzymes that end up in the phagosome. ${ }^{26}$ The neutrophil granules contain various enzymes, and bactericidal and biologically active products, which possess powerful destructive and regulatory

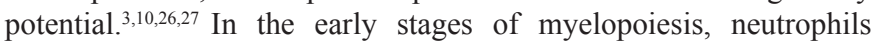
develop primary azurophilic granules, then secondary (specific) granules, while tertiary granules appear at later stages of myeloid cell maturation. ${ }^{9,10,26}$ The azurophilic granules in neutrophils contain antibacterial cationic proteins, acid hydrolase, and microbicidal enzymes with significant antimicrobial activity., ${ }^{3,26,28}$ The secondary granules contain lysozyme, lactoferrin, collagenase, heparinase, histaminase, complement activator, monocyte chemoattractant, and plasminogen. The tertiary neutrophil granules contain a store of acid hydrolases, gelatinases, proteinases, and hydrolytic matrix metalloproteinases. ${ }^{926,29,30}$ These enzymes are active against grampositive bacteria, fungi, and protozoa. ${ }^{3,9}$

\section{Neutrophil elastase}

$\mathrm{NE}$ is a serine protease and is located in the azurophilic granules of polymorphonuclear leukocytes..$^{31,32}$ This enzyme is present mainly in neutrophils, with small concentrations also found in monocytes, $\mathrm{T}$ lymphocytes and the free extracellular matrix. ${ }^{33,34}$ NE has significant proteolytic properties and participates in the degradation of extracellular matrix components (fibronectin, laminin, elastin, collagen and proteoglycans), thus damaging the lung and airway architecture..$^{32,35-37} \mathrm{NE}$ breaks down many soluble proteins, such as surfactant protein A, immunoglobulins and many protease inhibitors. $^{31,32,38,39} \mathrm{NE}$ stimulates leukocytes to infiltrate areas of inflammation, which leads to the accumulation of these cells in the microcirculation.

$\mathrm{NE}$ is an inflammatory regulator and can act as both an antiinflammatory and a pro-inflammatory agent. ${ }^{31,38} \mathrm{NE}$ participates in the breakdown of the protein components of bacterial walls, destroys endotoxins produced by enterobacteria, and is involved in the defense against gram-negative microorganisms. ${ }^{31} \mathrm{NE}$ has lytic activity in regards to IL- $1 \beta$, IL-2, IL- 6 , TNF- $\alpha$, and blocks the first and third complement receptors, which leads to reduced neutrophil adhesion and their migration into the tissues. ${ }^{32}$ Blood NE content is increased in pneumonia, bronchiectasis, chronic obstructive pulmonary disease and other conditions. ${ }^{31,40,41}$

Excessive NE production leads to destruction and goblet cell hyperplasia in the epithelial layer, mucus hypersecretion, mucociliary dysfunction, the development of fibroplastic processes in the connective tissue, bronchial remodeling and worsening of bronchial hyperreactivity. ${ }^{4,42} \mathrm{NE}$ worsens endothelial connections, thus leading to a reduction in capillary flow and the development of emphysema. ${ }^{31}$ Other protease groups are also involved in alveolar wall degradation in emphysema, such as matrix metalloproteinases (MMP), which are a product of neutrophils and macrophages. Unlike NE, MMP is released into the interstitial space in their inactive form. These proteases need to be activated by elastase to perform their lytic function.

NE activity is regulated by a proteinase inhibitor system: AAT, $\alpha 2$-macroglobulin, etc. A reduction in inhibitor levels leads to elastase activation and promotes inflammation. ${ }^{33,43}$ The imbalance between NE activity and its inhibitors may be due to altered production of neutrophil elastase, changes in the level or activity of the circulating inhibitors, or both concurrently. ${ }^{44}$

NE levels are raised in bronchoalveolar lavage fluid in patients with asthma. ${ }^{45}$ Neutrophils in asthma patients secrete NE and MMP in response to viral and bacterial activity. ${ }^{46}$ Eight-two percent of protease activity in the airways of patients with bronchiectasis is caused by NE, which slows down the phagocytic activity of phagocytes and the function of respiratory ciliated epithelium. ${ }^{47}$ In normal people, $\mathrm{NE}$ activity correlates with AAT concentration. ${ }^{48}$ A disturbance in this balance and an increase in the NE level forms the pathogenetic basis for the destruction of primarily interstitial elastic fibers with irreversible emphysematous changes. ${ }^{49}$

\section{$\alpha$ I-antitrypsin}

AAT is an example of serine protease inhibitors and plays an important role in the regulation of proteinase functions. ${ }^{50-52}$ AAT is synthesized predominantly by liver hepatocytes and to a significantly smaller degree by mononuclear phagocytes, neutrophils, and epithelial cells of the lung, intestines and kidney parenchyma. ${ }^{35,53,54}$ AAT binds to elastase, trypsin, chymotrypsin, thrombin, and bacterial proteases. Its most important physiological effect is NE inhibition. . $^{38,47,55}$ In inflammation, the AAT level can increase severalfold and is considered a marker of acute inflammation for this reason. ${ }^{56,57}$ The level of AAT can decrease idiopathically (hereditary AAT deficiency) or secondarily to a condition (nephrotic syndrome, reduction in the liver's synthetic function due to severe hepatocellular failure).$^{56}$

The normal AAT concentration in the blood as measured by nephelometry is $2.0-4.0 \mathrm{~g} / \mathrm{L}$. Serum AAT levels that are $\leq 35 \%$ of 
normal may lead to the development of emphysema. ${ }^{58}$ AAT is a nonspecific acute phase protein, whose level increases in inflammation. ${ }^{57}$ AAT concentration may rise in acute, subacute, and chronic infective conditions. Apart from its antiprotease activity, AAT neutralizes alpha defensin-1, leukotriene B4 and interleukin 8, which are powerful chemoattractants of neutrophils into the inflammatory area. ${ }^{59}$ The likely function of AAT, a natural wide-spectrum anti-inflammatory molecule, is the regulation of inflammatory reactions. ${ }^{60}$ An inflammatory reaction may be accompanied by an 11-fold increase in AAT concentration. ${ }^{61}$ AAT performs the function of immunoregulation and inhibits the neutrophil production of superoxide ${ }^{62}$

This study was carried out to investigate the functional status of neutrophils and their role in the formation of bronchopulmonary inflammation in patients with $\mathrm{BA}, \mathrm{COPD}, \mathrm{BA}+\mathrm{COPD}$ and CAP.

The study consisted of three sections.

I. Evaluation of parameters characterizing the functional status of neutrophils in patients with $\mathrm{BA}, \mathrm{COPD}, \mathrm{BA}+\mathrm{COPD}$ and $\mathrm{CAP}$, in comparison to healthy people.

II. Evaluation of the relationship between the functional status of neutrophils and signs of inflammation (CRP, ESR, leukocytosis), $\operatorname{IgG}$ and IgE to the allergens Strept. pneumoniae, Neisseria perflava, Haemofil. influenzae and Staph. aureus, fractional exhaled nitrogen oxide (FeNO) and pulmonary function.

III. Changes in the parameters of the functional status of neutrophils at different disease stages.

Patient clinical characteristics and study design: The study included 217 patients, aged 18 to 85 years. The following groups were created: group 1 - patients with BA (78 people), including mild bronchial asthma -31 patients, moderate bronchial asthma -39 patients, severe bronchial asthma -8 patients, group $2-$ patients with COPD (38 people), group 3 - patients with BA and COPD overlap syndrome (39 people), group 4 - patients with CAP (17 people). The control group consisted of two comparison groups:

a. patients with hypertension and IHD - 25 people aged 31 to 85 years, and

b. practically healthy volunteers -20 people aged 23 to 55 years.

Patients in the control group did not have allergies or oncological diseases, bronchopulmonary diseases, severe diabetes mellitus, liver, kidney or heart failure in their medical history, while concomitant conditions were in the stable remission phase. Patients were examined twice, before treatment during the acute disease phase and after treatment in the resolution phase. Patients were divided into groups according to the diagnosis and severity of BA, COPD and BA+COPD, which was determined in accordance with international guideline criteria (GINA, GOLD: 2011-2015, Spanish criteria 2012). Patients with $\mathrm{BA}$ and $\mathrm{BA}+\mathrm{COPD}$ were characterized by a mixed phenotype. Atopic and infection-dependent phenotypes had almost the same frequency $(83.8 \%$ and $88.9 \%$ respectively). Aspirin phenotype was found in $12.8 \%$ of patients, primarily in patients with severe BA, the steroid-dependent phenotype was present in $6.9 \%$ of patients with severe $\mathrm{BA}$, and the neuropsychological phenotype was present in $49.6 \%$ of patients with moderate and severe BA. In the COPD and $\mathrm{BA}+\mathrm{COPD}$ groups, the percentage of smokers was almost double the percentage in the BA and CAP groups. Allergic rhinitis was diagnosed in $80 \%$ of patients with BA of varying severity. Stage 1 respiratory failure was present in almost all patients with moderate and severe $\mathrm{BA}, \mathrm{COPD}$, and $\mathrm{BA}+\mathrm{COPD}$.

General clinical and laboratory methods: All study groups underwent clinical blood analysis and ESR, C-reactive protein, NE, AAT, phagocytic activity of neutrophils, respiratory burst (RB), pulmonary function, and FeNO tests. Blood samples were used for laboratory testing. The phagocytic activity of neutrophils and respiratory burst in blood serum were measured using flow cytometry with the Cytomics FC500 Beckman Coulter flow cytometer and the FagoFlowEx Kit (Exbio, Czech Republic). The phagocytic activity of neutrophils and respiratory burst was measured in $\%$.

The NE level was determined using the Human PMN-Elastase Platinum ELISA (Bioscience, USA) by the enzyme immunoassay method with the use of paired sera. NE was measured in $\mathrm{ng} / \mathrm{ml}$. Blood serum AAT was determined using kinetic nephelometry on the IMMAGE 800 analyzer with the AAT measuring set (Beckman Coulter, USA). AAT was measured in $\mathrm{g} / \mathrm{L}$. Blood serum $\mathrm{IgE}$ and IgG levels to Strept. pneumoniae, Neisseriaperflava, Haemofil. influenzae and Staph. aureus were measured at the Laboratory of Clinical Immunology and Molecular Diagnostics at the Center for Laboratory Diagnostics of the First Pavlov State Medical University of St. Petersburg. The Immunotex reagent set (Russia) was used to determine the immunoassay of allergen-specific IgE and $\operatorname{IgG}$ antibodies in blood serum using solid-phase non-competitive indirect immunoassay analysis. The measurement unit was $\mu \mathrm{g} / \mathrm{ml}$. A portable gas analyzer NObreath (Bedfont Scientific Limited, Great Britain) was used to measure FeNO in parts per billion (ppb) [114].

Pulmonary function tests were conducted at the Laboratory of Respiratory Physiology at the Rheumatology and Allergology Research Institute of the Clinical Research Center. Pulmonary function parameters were measured by spirometry with a flow-volume recording using the CareFusion MasterScreen system in accordance with ATS/ERS criteria before and after the inhalation of salbutamol/ fenoterol.

Analysis results for parameters characterizing the functional status of neutrophils in patients with BA, COPD, BA+COPD and CAP: Table 1 contains the analysis results of parameters characterizing the functional status of neutrophils.

Distribution of the absolute neutrophil number in the peripheral circulation in patients with BA, COPD, BA+COPD, CAP and comparison groups: In patients with mild $\mathrm{BA}$ and the comparison groups, the average neutrophil number was within the normal range. In the CAP group, the number of neutrophils was significantly higher than in healthy people and patients with HT and IHD $(\mathrm{p}=0.024$ and $\mathrm{p}=0.012)$. A high neutrophil content was found in patients with $\mathrm{BA}+\mathrm{COPD}(7.55 \pm 2.53)$ and $\mathrm{COPD}(8.45 \pm 3.92)$, which was significantly higher than in patients with $\mathrm{CAP}$ ( $\mathrm{p}=0.001$ and $\mathrm{p}=0.001$ ). Patients with severe BA had the highest neutrophil levels (9.66 \pm 3.08$)$. In patients with CAP, the neutrophil level on admission was significantly lower than in patients with severe BA, patients with $\mathrm{BA}+\mathrm{COPD}$, and patients with $\mathrm{COPD}(\mathrm{p}<0.05)$. It is likely that the low neutrophilia in patients with CAP was due to the antibacterial therapy received by the majority of patients prior to hospital admission. In patients with mild and moderate BA and patients with COPD, there was a direct correlation between the absolute number of neutrophils and the NE level $(p<0.05)$ which is likely due to NE being a product of neutrophil degranulation. 
The neutrophilia found in patients with moderate and severe BA, $\mathrm{BA}+\mathrm{COPD}, \mathrm{COPD}$ and $\mathrm{CAP}$ was due to inflammation. It is known that the use of high doses of corticosteroids can also lead to neutrophilia. The neutrophil content was significantly higher in patients with BA using inhaled and oral corticosteroids, as compared to patients who did not receive corticosteroids ( $\mathrm{p}=0.028$ and $\mathrm{p}=0.000$ ). The levels of neutrophils, NE and PAN were significantly higher in patients receiving parenteral corticosteroids, as compared to patients who did not receive this treatment $(\mathrm{p}=0.000, \mathrm{p}=0.0006, \mathrm{p}=0.008)$. When analyzing all the groups together, it was found that levels of AAT, NE and neutrophils were higher in people requiring antibacterial therapy $(\mathrm{p}=0.000, \mathrm{p}=0.000$ and $\mathrm{p}=0.000)$. The neutrophil level was statistically higher in older patients than in younger people $(p=0.0007)$. The levels of neutrophils, NE and AAT were significantly higher in smokers than non-smokers $(\mathrm{p}=0.000, \mathrm{p}=0.012$ and $\mathrm{p}=0.001)$.

Table I Results of neutrophil, NE,AAT, pulmonary function and respiratory burst analysis

\begin{tabular}{llllll}
\hline Study groups & Neutr. & NE & AAT & PAN & Respiratory burst \\
\hline Mild BA & $3.74 \pm 1.72$ & $156.6[109.2 ; 312.7]$ & $1.56[1.38 ; 1.8]$ & $92.2[86.7 ; 95.5]$ & $22.7[12.4 ; 32.7]$ \\
Moderate BA & $6.02 \pm 3.08$ & $206.1[142.2 ; 393.3]$ & $1.57[1.45 ; 1.8]$ & $92.5[89.9 ; 94.7]$ & $22.6[16.2 ; 32.6]$ \\
Severe BA & $9.66 \pm 3.08$ & $200.6[161.5 ; 306.4]$ & $1.71[1.63 ; 1.81]$ & $92.3[87.3 ; 92.9]$ & $15.1[11.9 ; 30.1]$ \\
BA+COPD & $7.55 \pm 2.52$ & $226.2[171.0 ; 366.8]$ & $1.61[1.56 ; 1.82]$ & $93.4[88.0 ; 97.0]$ & $20.6[15.7 ; 27.9]$ \\
COPD & $8.45 \pm 3.92$ & $385.5[207.4 ; 574.6]$ & $1.77[1.59 ; 1.97]$ & $90.55[82.85 ; 94.36]$ & $18.75[14.0 ; 26.55]$ \\
CAP & $4.84 \pm 2.04$ & $378.6[275.3 ; 458.5]$ & $2.73[2.11 ; 3.01]$ & $86.7[78.3 ; 93.4]$ & $17.3[11.6 ; 24.7]$ \\
Practically & $3.29 \pm 1.06$ & $198.9[107.8 ; 328.2]$ & $1.5[1.45 ; 1.69]$ & $86.8[81.6 ; 91.35]$ & $21.4[10.0 ; 25.8]$ \\
healthy & $3.33 \pm 0.91$ & $138.0[89.1 ; 262.7]$ & $1.54[1.41 ; 1.67]$ & $89.8[85.9 ; 92.7]$ & $26.1[21.1 ; 33.6]$ \\
HT+IHD & & & &
\end{tabular}

Note: for samples characterized by a normal distribution, the mean value and standard deviation ( $\mathbf{M} \pm \sigma)$ are listed (parametric statistics); for samples characterized by a non-normal distribution, the median and interquartile ranges are listed.

NE in the different study groups: The highest NE values were found in patients with COPD (385.55 [207.4; 574.6]) and CAP (378.6 $[275.3 ; 458.5])$, which were statistically different from the values in healthy people and those with HT and IHD $(p<0.05)$. NE levels in patients with mild, moderate and severe BA and patients with $\mathrm{BA}+\mathrm{COPD}$ did not differ significantly from healthy people and between themselves (mild BA and moderate $\mathrm{BA}, \mathrm{p}=0.245$; mild $\mathrm{BA}$ and severe BA, $\mathrm{p}=0.295$, moderate $\mathrm{BA}$ and severe $\mathrm{BA}, \mathrm{p}=0.939$ ). NE levels in patients with mild, moderate and severe BA and patients with BA+COPD were significantly lower than in patients with COPD and patients with CAP $(\mathrm{p}<0.05)$.

AAT in the different study groups: The highest AAT values were found in patients with CAP, with a median score of 2.73 [2.11; 3.01]. In patients with mild and moderate BA, the AAT level was not statistically different from the level in healthy people $(p>0.05)$ and was significantly lower than in patients with $\mathrm{BA}+\mathrm{COPD}$ and patients with CAP (mild BA and COPD, $p=0.029$; mild BA and CAP, $p=0.000$; moderate $\mathrm{BA}$ and COPD, $\mathrm{p}=0.018$, moderate $\mathrm{BA}$ and $\mathrm{CAP}, \mathrm{p}=0.000$ ). Patients with severe BA, BA+COPD, COPD and CAP had higher levels of AAT than healthy people and patients with HT and IHD $(p<0.05)$. These findings confirm the idea that AAT reflects an acute inflammatory process.

PAN in the different study groups: The phagocytic activity of neutrophils level was statistically higher in patients with mild and moderate BA and BA+COPD than in healthy people $(\mathrm{p}<0.05)$. The phagocytic activity of neutrophils was significantly higher in patients with moderate $\mathrm{BA}$ and $\mathrm{BA}+\mathrm{COPD}$ as compared to patients with $\mathrm{CAP}$ $(\mathrm{p}=0.029, \mathrm{p}=0.031)$. The phagocytic activity of neutrophils in patients with CAP and COPD was not statistically different to healthy people $(p<0.05)$. The phagocytic activity of neutrophils was most increased in patients with $\mathrm{BA}$ and patients with $\mathrm{BA}+\mathrm{COPD}$.

Respiratory burst in the different study groups: The respiratory burst was lower in patients with severe BA, COPD and CAP than in healthy people, but this difference was not statistically significant $(p>0.05)$. The respiratory burst in patients with mild and moderate $\mathrm{BA}$, patients with $\mathrm{BA}+\mathrm{COPD}$ and patients with CAP did not differ from that in healthy people $(\mathrm{p}>0.05)$.

Relationship between neutrophils, NE, AAT, PAN, and respiratory burst: A direct correlation was found in patients with mild and moderate BA and patients with COPD between the absolute number of neutrophils and the NE level $(\mathrm{p}<0.05)$, which was to be expected since $\mathrm{NE}$ is a product of neutrophil degranulation. There were no significant correlations found between these parameters in other groups $(p>0.05)$. There was a positive correlation in patients with CAP between the absolute number of neutrophils and AAT $(\mathrm{p}<0.01)$, which is likely due to AAT activation in response to the inflammatory process, which is accompanied by an increase in the number of neutrophils.

There was a negative correlation between NE and the absolute number of eosinophils in the peripheral circulation $(\mathrm{p}<0.001$ and $\mathrm{p}<0.01$ ) in patients with moderate BA and COPD. It is likely that the eosinophilia is related to the start of the resolution of the inflammatory process, which is accompanied by a reduction in NE and reflects different phases of inflammation. An overall correlation analysis demonstrated that all the study subjects had a direct link between NE and AAT $(p<0.001)$. This link was statistically evident independent of the study group, which can be expected since AAT control the function of NE $[4,122,135]$. AAT and NE levels were determined by inflammation severity, which is low in patients with mild and moderate BA, moderate in patients with severe BA and COPD, and high in patients with COPD and CAP.

Correlation between the studied parameters and allergies: All the subjects were divided into 2 groups: the first group consisted of patients with allergic conditions, which included patients with BA and patients with $\mathrm{BA}+\mathrm{COPD}(\mathrm{n}=117)$, while the second group had no allergic conditions and consisted of patients with COPD, patients with CAP and people from the comparison group $(n=100)$. There were no statistically significant differences in NE and AAT levels $(\mathrm{p}=0.261$ and $\mathrm{p}=0.109)$ and respiratory burst $(\mathrm{p}=0.592)$ between the group with allergies and the group without allergies. Patients with allergies were 
characterized by a higher level of phagocytic activity of neutrophils as compared to the subjects without allergies $(\mathrm{p}=0.000)$.

NE, AAT, PAN, and respiratory burst in relation to FeNO values: The highest FeNO levels were found in patients with severe BA (34.8 $[6.33 ; 64.50])$ and CAP $(27.7[15.67 ; 35.33])$. Positive correlations were found between FeNO and NE in patients with severe BA, and FeNO and PAN in patients with CAP $(\mathrm{p}<0.05)$, who were the patients with the highest FeNO values.

Neutrophils, NE, AAT, PAN and respiratory burst as related to pulmonary function: There was a negative correlation between increased neutrophil numbers and the AAT levels and spirometry flow scores (MEF50, FEF25-75\%) in patients with mild BA, which confirms the negative link between inflammation severity and bronchial passability $(\mathrm{p}<0.05)$. A positive correlation between PAN and MEF75 $(\mathrm{p}<0.05)$ was found in patients with mild BA, which may reflect the mechanism of preventing obstruction in the distal bronchi. Table 2 shows the correlation analysis of pulmonary function with the parameters that characterize the functional status of neutrophils in patients with $\mathrm{BA}+\mathrm{COPD}$.

Table 2 Correlation analysis of pulmonary function scores and parameters characterizing the functional status of neutrophils in patients with BA+COPD (Spearman's correlation coefficient)

\begin{tabular}{|c|c|c|c|c|c|c|}
\hline Parameter & $\mathbf{N}$ & Neutrophils & NE & AAT & $\begin{array}{l}\text { Phagocytic activity } \\
\text { of neutrophils }\end{array}$ & Respiratory burst \\
\hline $\mathrm{FEV}_{1} \%$ & 39 & -0.01 & -0.275 & $-0.48 I^{* *}$ & -0.088 & -0.154 \\
\hline $\mathrm{FEV}, \% \#$ & 39 & 0.097 & -0.24 & -0.338 & -0.062 & -0.106 \\
\hline PFER\% & 39 & 0.026 & -0.038 & $-0.409 * *$ & -0.16 & -0.129 \\
\hline MEF50\% & 39 & 0.036 & -0.309 & $-0.511 *$ & -0.034 & -0.168 \\
\hline MEF50\%\# & 39 & 0.085 & -0.295 & $-0.384 * *$ & -0.05 & -0.164 \\
\hline MEF75\% & 39 & 0.075 & $-0.317^{* * *}$ & $-0.445 * *$ & -0.125 & -0.171 \\
\hline MEF75\%\# & 39 & 0.095 & -0.311 & $-0.447^{* *}$ & -0.045 & -0.221 \\
\hline FEF25-75\% & 39 & 0.031 & -0.313 & $-0.493 *$ & -0.194 & -0.083 \\
\hline FEF25-75\%\# & 39 & 0.136 & -0.312 & $-0.395 * *$ & -0.037 & -0.168 \\
\hline $\mathrm{FEV}_{1} / \mathrm{FVC} \%$ & 39 & -0.022 & $-0.338 * * *$ & $-0.45 I^{* *}$ & -0.228 & -0.039 \\
\hline $\mathrm{FEV}_{1} / \mathrm{FVC} \%^{\#}$ & 39 & 0.04 & $-0.325 * * *$ & $-0.347^{* * *}$ & -0.026 & -0.215 \\
\hline $\mathrm{FEV} / \mathrm{FVCact}$ & 39 & 0.006 & -0.313 & $-0.350 * * *$ & -0.012 & -0.211 \\
\hline
\end{tabular}

\#measurement done after bronchodilator inhalation

*statistically significant correlation with $\mathrm{p}<0.001$

**statistically significant correlation with $p<0.01$

*** statistically significant correlation with $\mathrm{p}<0.05$

Patients with BA + COPD were characterized by a greater number of identified negative correlations between AAT and NE with pulmonary function scores. These correlations were absent in patients with BA and patients with COPD. The negative link between AAT level and all the parameters of bronchial passability on the spirogram was related to the fact that AAT reflects an acute inflammatory process. An increase in AAT and associated inflammation was accompanied by a deterioration in bronchial passability. Table 3 shows a correlation analysis of pulmonary function with the parameters that characterize the functional status of neutrophils in patients with CAP.

Similar to patients with BA+COPD, patients with CAP demonstrated only negative correlations between AAT, PAN, respiratory burst and neutrophils, and pulmonary function scores. An increase in neutrophil numbers in the peripheral circulation and their phagocytic activity, an increase in AAT, respiratory burst and FeNO levels, which occurs during inflammatory exacerbation, was accompanied by a reduction in bronchial passability and flow rates during spirometry in patients with CAP.

There was a lack of statistically significant correlations between AAT, NE, PAN and pulmonary function parameters in patients with
COPD ( $>0.05$ ). Patients with severe BA had a positive correlation between AAT, NE and PAN with pulmonary function parameters $(p<0.05)$. Patients with severe BA who received glucocorticoid therapy demonstrated a positive correlation between AAT, NE, PAN and FeNO, and pulmonary function parameters. Single positive correlations were found in patients with mild, moderate, and severe BA between the neutrophil function parameters and pulmonary function characteristics, but, in general, there was a lack of a correlation between the examined parameters.

The correlation analysis of the relationship between neutrophil function parameters and pulmonary function characteristics allows us to conclude that these relationships are negative in nature in patients with $\mathrm{BA}+\mathrm{COPD}$. The same conclusion can be confidently made upon the examination of patients with CAP. Clinical signs of an active inflammatory process were absent in the respiratory organs of patients with $\mathrm{BA}+\mathrm{COPD}$, and there was a negative correlation between pulmonary function characteristics and the parameters characterizing neutrophil function. This means that patients with BA+COPD had an active inflammatory process in the airways that was not clinically evident but was evident from the levels of parameters characterizing 
neutrophil status, particularly AAT. The pathological process in patients with $\mathrm{BA}+\mathrm{COPD}$ is not just the sum of BA and COPD but a special pathological condition, with subclinical airway inflammation that is best identified by measuring AAT.

Table 3 Correlation analysis of pulmonary function scores and parameters characterizing the functional status of neutrophils in patients with CAP (Spearman's correlation coefficient)

\begin{tabular}{|c|c|c|c|c|c|c|}
\hline Parameter & $\mathbf{N}$ & Neutrophils & NE & AAT & PAN & Respiratory burst \\
\hline $\mathrm{FEV}, \%$ & 7 & -0.429 & 0.25 & -0.75 & $-0.786 * * *$ & -0.429 \\
\hline $\mathrm{FEV}_{1} \%{ }^{\#}$ & 7 & -0.464 & 0.325 & $-0.893 * *$ & $-0.964 *$ & -0.714 \\
\hline PFER\% & 7 & -0.607 & 0.143 & $-0.785^{* * *}$ & -0.75 & $-0.786 * * *$ \\
\hline PFER\%\# & 7 & -0.643 & -0.107 & $-0.893 * *$ & $-0.857 * *$ & -0.607 \\
\hline MEF50\% & 7 & -0.429 & 0.071 & -0.75 & $-0.7 \mid 4$ & -0.321 \\
\hline MEF50\%\# & 7 & $-0.57 \mid$ & 0.214 & $-0.786 * * *$ & -0.75 & -0.393 \\
\hline MEF75\% & 7 & -0.321 & -0.357 & -0.536 & -0.392 & 0.012 \\
\hline MEF75\% ${ }^{\#}$ & 7 & -0.75 & 0.286 & -0.357 & -0.321 & -0.321 \\
\hline FEF $25-75 \%$ & 7 & $-0.57 \mid$ & -0.179 & $-0.786 * * *$ & -0.679 & -0.179 \\
\hline FEF25-75\%\# & 7 & -0.964 & 0.071 & $-0.786 * * *$ & -0.643 & -0.429 \\
\hline $\mathrm{FEV}_{1} / \mathrm{FVC} \%$ & 7 & -0.179 & -0.107 & $-0.929 * *$ & -0.429 & -0.143 \\
\hline $\mathrm{FEV}_{1} / \mathrm{FVC} \%^{\#}$ & 7 & $-0.786 * * *$ & -0.143 & $-0.929 * *$ & $-0.82 I^{* * * *}$ & -0.464 \\
\hline $\mathrm{FEV}_{1} / \mathrm{FVCact}$ & 7 & -0.321 & -0.035 & $-0.929 * *$ & -0.05 & -0.023 \\
\hline
\end{tabular}

\#measurement done after bronchodilator inhalation

*statistically significant correlation with $\mathrm{p}<0.001$

**statistically significant correlation with $\mathrm{p}<0.01$

$* * *$ statistically significant correlation with $\mathrm{p}<0.05$

Changes in the functional status of neutrophils during different disease phases considering treatment efficacy in patients with BA, BA+COPD, COPD and CAP: Patients were prescribed therapy in accordance with the treatment recommendations for these conditions (PPO, GINA, GOLD). Patients with BA received combination drugs (inhaled corticosteroids and long-acting bronchodilators) as standard therapy. Patients with moderate and severe BA were prescribed nebulizer therapy with bronchodilators and mucolytics in addition to standard therapy, and if required, oral or intravenous systemic corticosteroids (for patients with severe BA). Antibacterial therapy was used in cases of active infection, mainly third-generation cephalosporins, and nebulizer therapy using mucolytics and bronchodilators. Patients with CAP received antibacterial therapy, mainly penicillin or third-generation cephalosporins, as well as mucolytics.

A repeat clinical blood analysis, including AAT, NE, PAN, respiratory burst and FeNo levels was performed 7-10 days after hospitalization and drug therapy. Patients with mild BA did not demonstrate any significant changes in the study parameters after treatment $(\mathrm{p}<0.05)$, which is likely due to the mild course of the disease. Patients with moderate BA had a statistically significant decrease in FeNO and neutrophil content levels $(\mathrm{p}=0.000$ and $\mathrm{p}=0.042)$ after treatment. The eosinophil content increased significantly but was within the reference values $(p=0.009)$. Patients with severe BA demonstrated a significant reduction in neutrophil content $(\mathrm{p}=0.036)$ and a statistically significant increase in eosinophil content within normal values $(p=0.012)$ after drug therapy.
Patients with BA+COPD showed a positive change in AAT, PAN, ESR and FeNO values, evidenced by a reduction in their levels $(p<0.05)$ and a significant increase in the number of leukocytes and eosinophils $(\mathrm{p}<0.05)$ after treatment. The increase in eosinophil values was within normal range $(\mathrm{p}=0.000)$. The increase in leukocyte numbers in patients with $\mathrm{BA}+\mathrm{COPD}$ is likely related to the treatment with corticosteroids. It is worth noting that patients with $\mathrm{BA}+\mathrm{COPD}$ had a greater positive response to treatment as compared to patients with BA or COPD.

Patients with COPD demonstrated a significant reduction in AAT, FeNO and ESR levels $(\mathrm{p}=0.000, \mathrm{p}=0.000, \mathrm{p}=0.038)$ after treatment, while the eosinophil content increased within the normal range. Patients with CAP had significantly positive changes in AAT, ESR and FeNO values $(\mathrm{p}=0.000, \mathrm{p}=0.002, \mathrm{p}=0.005)$ after treatment, as well as normalization of clinical, laboratory and $\mathrm{X}$-ray signs.

\section{Discussion of obtained results}

To determine the involvement of neutrophils in the airway inflammation process in patients with $\mathrm{BA}, \mathrm{COPD}, \mathrm{BA}+\mathrm{COPD}$ and $\mathrm{CAP}$, we measured the neutrophil numbers in peripheral circulation, their phagocytic activity, their ability to carry out respiratory burst, and NE and AAT levels. Patients with mild BA were characterized by normal neutrophil levels. The neutrophil content increased with increasing BA severity, particularly in patients with severe BA, which can be explained not only by the features of BA but also corticosteroid treatment. Neutrophilia was also present with patients with $\mathrm{BA}+\mathrm{COPD}, \mathrm{COPD}$ and CAP. The neutrophilia found in patients 
with moderate and severe $\mathrm{BA}, \mathrm{BA}+\mathrm{COPD}, \mathrm{COPD}$ and $\mathrm{CAP}$ may be due to inflammation and corticosteroid therapy. The NE level was normal in patients with BA, irrespective of severity, and in patients with $\mathrm{BA}+\mathrm{COPD}$. The highest NE level was found in patients with COPD and CAP. The NE concentration was more than 3 times higher in patients with COPD as compared to healthy people. ${ }^{63}$ R.S. Pawar and S.A. Abhang (2015), as well as S. Bchir, H. Nasr, S. Bouchet (2016) also found significantly higher blood serum NE levels in patients with COPD.${ }^{64,65}$ Patients with COPD and CAP had the highest NE levels, which confirms the presence of a significant inflammatory process.

The AAT level was statistically significantly increased in patients with severe BA, BA+COPD, COPD and CAP. The highest AAT level was found in patients with CAP. None of the study groups had AAT deficiency. The AAT level rose with increasing BA severity and the addition of COPD, which is likely due to the prevention of NE increase, with NE levels being within the normal range in these groups. The NE level was significantly higher in patients with COPD and CAP, which was accompanied by an imbalance between proteases and antiprotease $\mathrm{s}^{36,66}$ and an increase in the AAT concentration.

The study of different combinations of NE and AAT levels was of particular interest. Patients with mild BA and those in the comparison groups had low levels of NE and AAT, which indicates low neutrophil activity and minimal inflammation. The percentage of patients with moderate NE and AAT levels increased with greater BA severity. The highest percentage of patients with high NE and AAT levels was found in patients with CAP and COPD, which is related to the pronounced inflammation and high neutrophil activity. The phagocytic activity of neutrophils was increased in all patients with BA irrespective of disease severity, as well as in patients with $\mathrm{BA}+\mathrm{COPD}$. This corresponds to the published data. ${ }^{67,68}$ It is likely that the increase in the phagocytic activity of neutrophils in patients with $\mathrm{BA}$ and $\mathrm{BA}+\mathrm{COPD}$ is caused by a persisting chronic inflammatory process.

Patients with COPD and CAP did not significantly differ from practically healthy people in terms of PAN. Published data on phagocytosis function in patients with COPD is ambiguous. Previous articles note both a decrease in the phagocytic activity of neutrophils during disease resolution ${ }^{69}$ and low phagocytic activity of neutrophils during the acute phase and disease resolution. ${ }^{70}$ The respiratory burst level in all patient groups (BA, BA+COPD, COPD and CAP) was comparable to that in practically healthy people. A correlation analysis of all the study subjects irrespective of clinical groups showed a statistically significant positive link between NE and AAT, which is understandable as AAT controls NE function by being its inhibitor. ${ }^{38,48,55}$

A positive correlation was found between the NE level and the neutrophil number in patients with mild and moderate BA, and COPD. Patients with moderate BA and COPD had a negative correlation between the NE level and the absolute number of eosinophils in the peripheral circulation. Eosinophilia was related to a resolution of the inflammatory process, which was accompanied by a reduction in NE and reflected a different phase of inflammation. Patients with CAP had a positive correlation between neutrophil numbers and the AAT level, with AAT being activated in significant inflammation and accompanied by an increase in neutrophil numbers. The positive link between neutrophils and NE, and the negative link between eosinophils and NE in patients with BA and COPD were likely because neutrophils and eosinophils reflect different phases of the inflammatory process.
The relationship between the parameters characterizing the functional status of neutrophils and FeNO was also analyzed. The FeNO level was significantly higher in patients with severe BA and CAP as compared to patients in other groups, which correlates with data in the literature. ${ }^{71-74}$ The FeNO level was significantly higher in patients with mild and moderate $\mathrm{BA}$ and $\mathrm{BA}+\mathrm{COPD}$ than in practically healthy people. The FeNO level was normal in patients with COPD, which corresponds to data in the literature. ${ }^{75}$ There were significant positive correlations between $\mathrm{NE}$ and the number of leukocytes in patients with mild and moderate BA and patients with COPD, which is probably related to the unidirectional involvement of $\mathrm{NE}$ and leukocytes in the pathogenesis of BA and COPD.

Negative correlations were found between increased neutrophil and AAT levels, and spirometry flow rates and indicators of bronchial obstruction in patients with $\mathrm{BA}+\mathrm{COPD}$ and CAP. AAT is a protein typically present in the acute inflammatory phase. Increased AAT levels indicate active inflammation, which negatively affects the functional state of the bronchopulmonary system and bronchial passability in patients with $\mathrm{BA}+\mathrm{COPD}$. It must be noted that clinical signs of active inflammation were absent in these patients. Similar significant negative links between AAT and other indicators of neutrophil function, and the characteristics of the functional status of respiratory organs were also found in patients with CAP, in whom active airway inflammation is obvious. Significant negative correlations between AAT and indicators characterizing bronchial obstruction and bronchospasm were absent in patients with mild, moderate and severe BA and patients with COPD (Table 4). This allows us to hypothesize that the pathological process in patients with BA+COPD is not simply the sum of these two diseases but a qualitatively new pathological condition, founded on inflammation, which is demonstrated by AAT values.

To determine what this inflammation was related to, the patients' blood serum was studied for the presence of $\operatorname{IgG}$ and $\operatorname{IgE}$ to Strept. pneumoniae, Neisseria perflava, Haemofil. influenzae and Staph. aureus (Figure 1-5). Elevated levels of IgG antibodies to Strept. pneumoniae, Neisseria perflava and Haemofil. influenzae were found only in patients with BA+COPD, while antibody levels to these three bacterial antigens were not elevated in all the other patient groups and comparison groups. IgE levels to these three bacterial antigens were not elevated. IgG and IgE levels to Staph. aureus were not increased in patients with $\mathrm{BA}+\mathrm{COPD}$ and all the other patient groups. This allows us to believe that the inflammation in patients with $\mathrm{BA}+\mathrm{COPD}$ is associated with the abovementioned bacterial infection, is not accompanied by sensitization or pronounced clinical symptoms but with bronchial obstruction of the bronchi and raised AAT levels. We did not find such characteristics of patients with BA+COPD in the available literature.

\section{Changes in the studied parameters in patients with BA, BA+COPD, COPD and CAP after the conducted treatment}

An analysis of the changes in the studied parameters after therapy was performed. Complete or partial disease remission was achieved because of the conducted treatment. Table 5 presents a summary of the parameter changes after therapy. In patients with severe BA, a significant decrease in activity parameters, except neutrophilia, did not occur despite combination therapy including corticosteroids, although a clinically positive result was achieved. Signs of systemic inflammation were found in patients with $\mathrm{BA}+\mathrm{COPD}$ during the 
The functional status of neutrophils in patients with bronchial asthma, chronic obstructive pulmonary disease, bronchial asthma with chronic obstructive pulmonary disease, and community-acquired

acute exacerbation phase, such as an increase in the neutrophil, NE, medications, and these positive changes were more significant than AAT, and ESR values. There was a significant decrease in the AAT, those in patients with mild, moderate, and severe BA and patients with respiratory burst, ESR, and FeNO values with the administration of COPD.

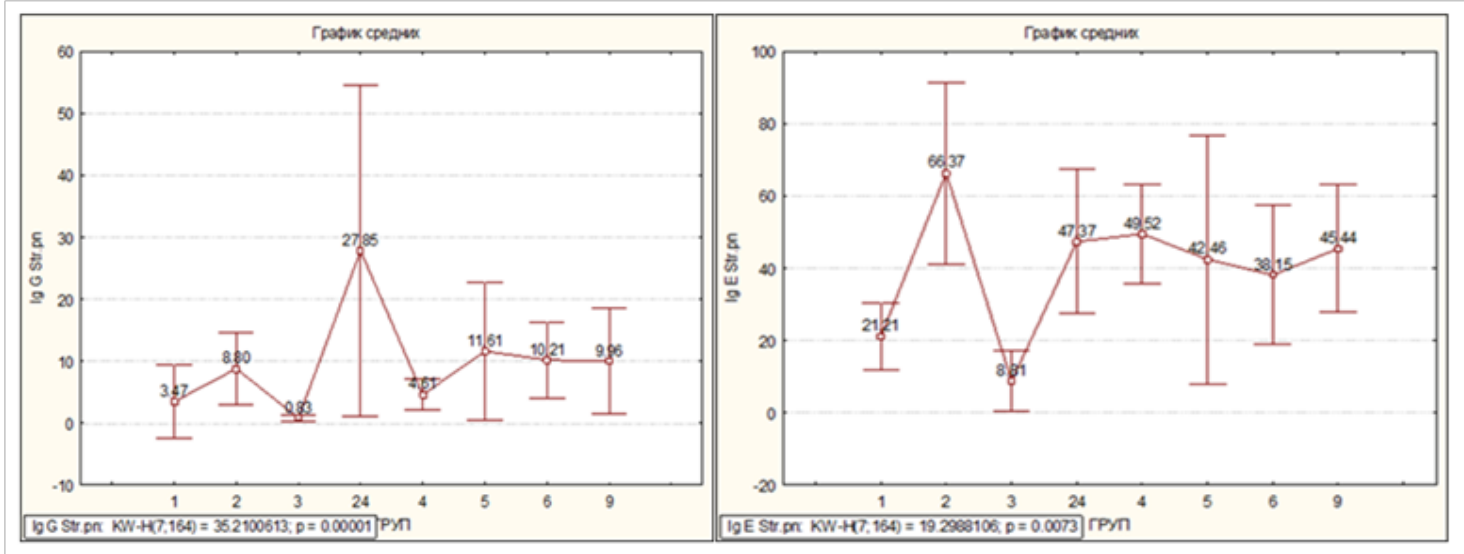

Figure I Distribution of $\lg G$ and $\lg E$ levels to $S$. pneumoniae in all study subjects.

Note: I, mild BA; 2, moderate BA; 3, severe BA; 24, BA+COPD; 4, COPD; 5, CAP; 6, practically healthy; 9, HT+IHD

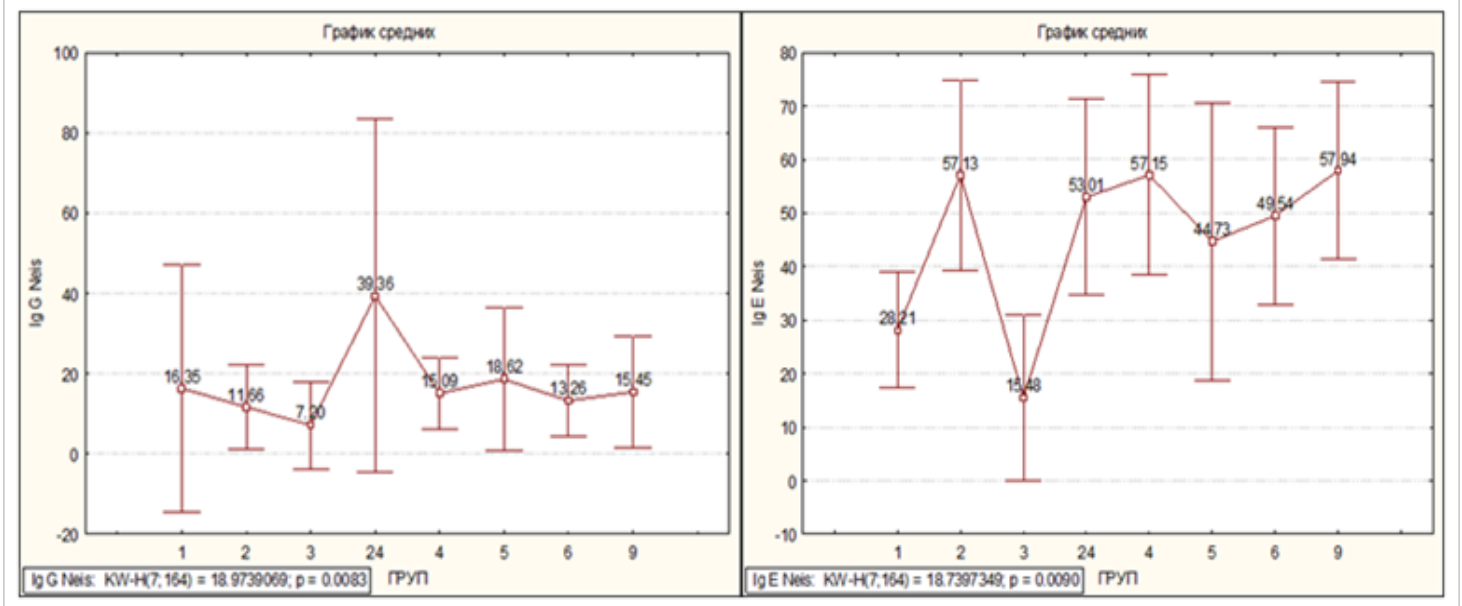

Figure 2 Distribution of IgG and lgE levels to N. perflava in all study subjects.
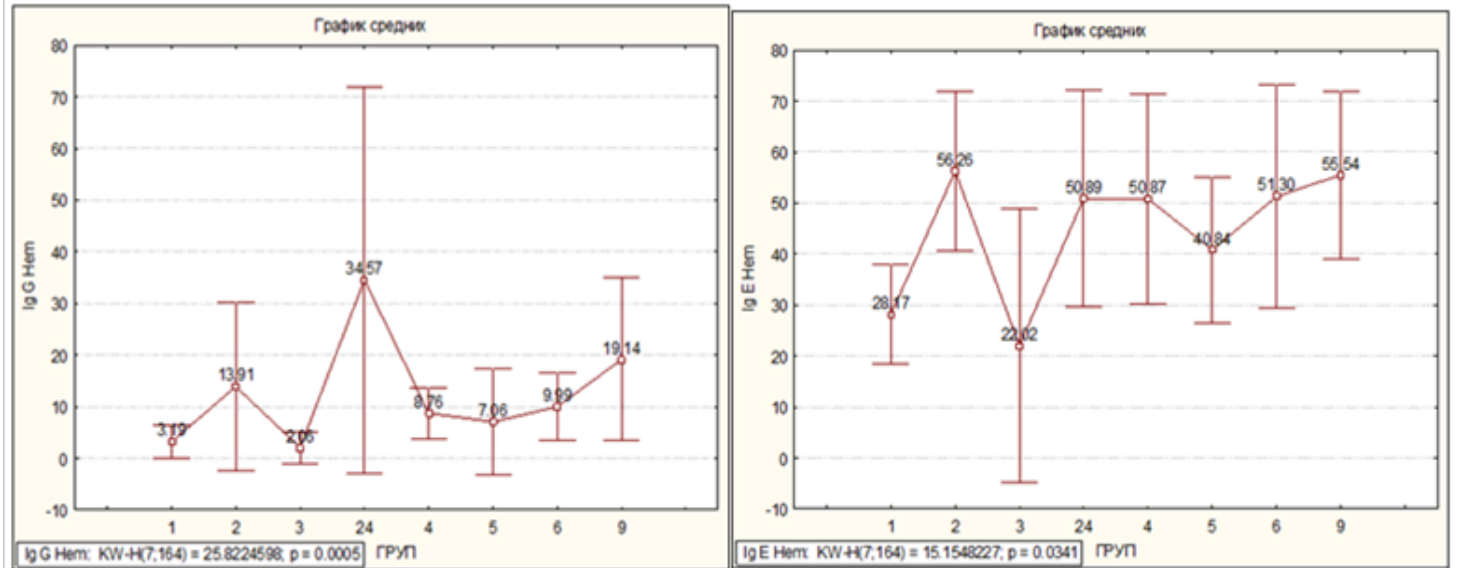

Figure 3 Distribution of $\lg G$ and $\lg E$ levels to $H$. influenzae in all study subjects. 

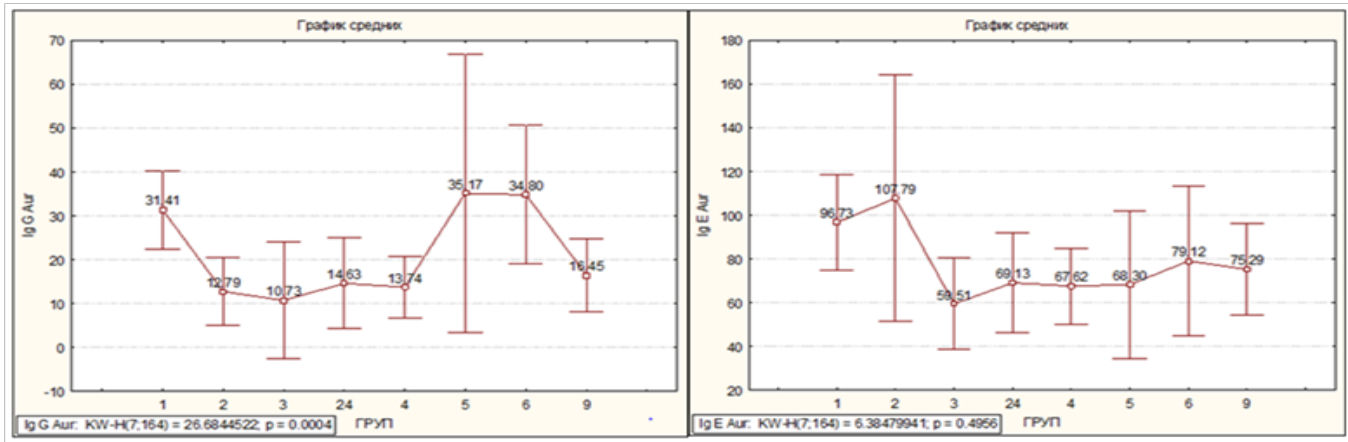

Figure 4 Distribution of $\lg G$ and $\lg E$ levels to $S$. aureus in all study subjects.
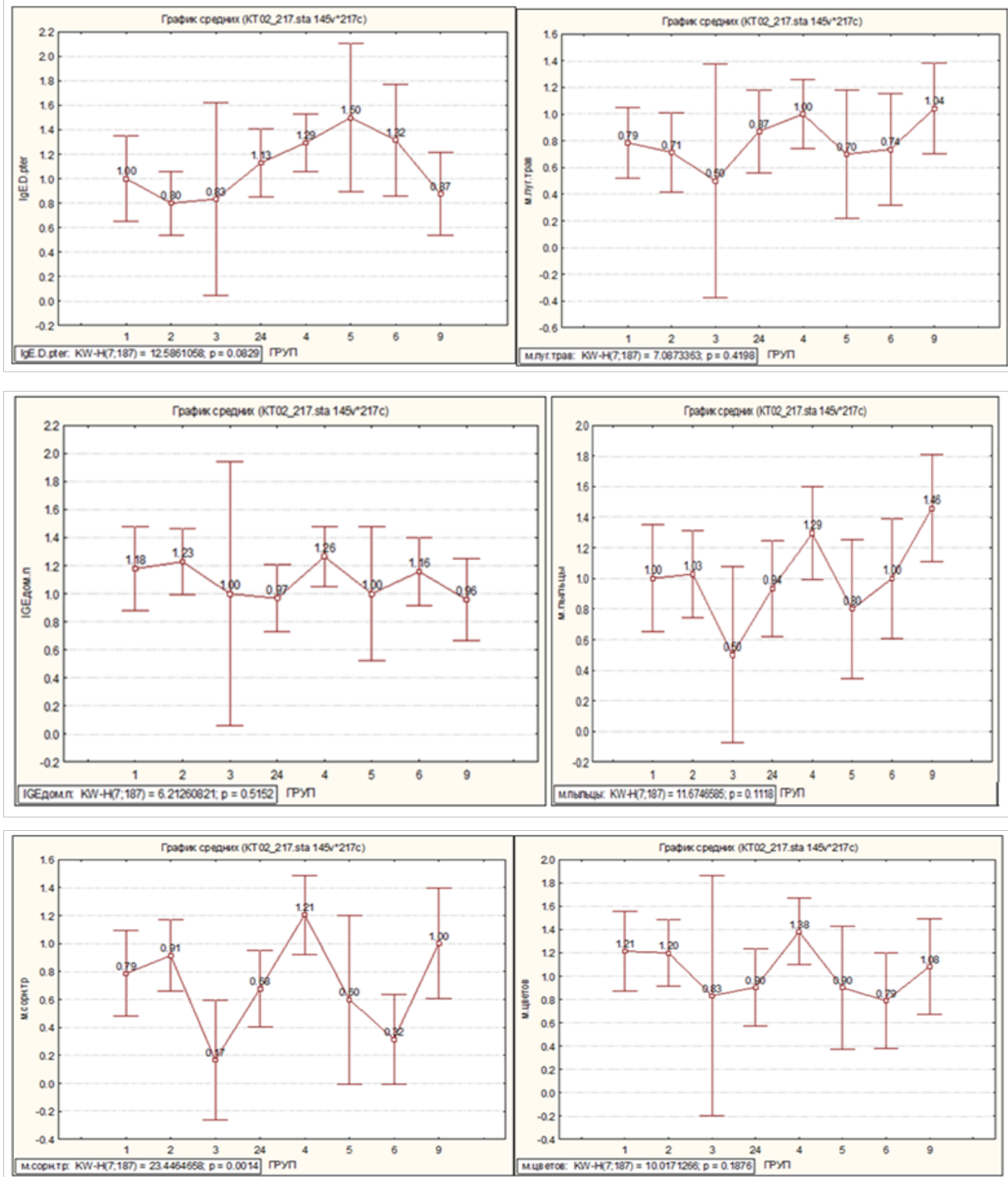

Figure 5 Distribution of IgE levels to D. pteronyssinus, home dust, grass pollen mix, tree, weed and flower pollen in all study subjects.

Citation: Fedoseev GB, Trofimov VI, Negrutsa KV, et al. The functional status of neutrophils in patients with bronchial asthma, chronic obstructive pulmonary disease, bronchial asthma with chronic obstructive pulmonary disease, and community-acquired pneumonia.J Lung Pulm Respir Res. 20I8;5(2):5I-63. DOI: 10.15406/jprr.2018.05.00162 
The functional status of neutrophils in patients with bronchial asthma, chronic obstructive pulmonary disease, bronchial asthma with chronic obstructive pulmonary disease, and community-acquired pneumonia

Table 4 Correlations between pulmonary function parameters and AAT in all the study groups

\begin{tabular}{|c|c|c|c|c|c|c|}
\hline Parameter & Mild BA, n=31 & Moderate BA, n=39 & Severe BA, $n=8$ & BA+COPD, $n=39$ & $\begin{array}{l}\text { COPD, } \\
n=38\end{array}$ & $C A P, n=17$ \\
\hline $\mathrm{FEV}_{1} \%$ & -0.224 & 0.168 & $0.762 * * *$ & $-0.48 I * *$ & -0.082 & -0.75 \\
\hline $\mathrm{FEV}_{1} \%$ \% & -0.13 & 0.009 & $0.714 * * *$ & $-0.338 * * *$ & -0.027 & $-0.893 * *$ \\
\hline PFER\% & -0.143 & 0.192 & 0.524 & $-0.409 * *$ & -0.153 & $-0.785^{* * *}$ \\
\hline PFER\% ${ }^{\#}$ & -0.007 & 0.122 & 0.5 & -0.277 & -0.109 & $-0.893 * *$ \\
\hline MEF50\% & $-0.403 * * *$ & 0.195 & 0.251 & $-0.511 *$ & -0.015 & -0.07 \\
\hline MEF50\%\# & -0.234 & 0.116 & 0.214 & $-0.384 * *$ & -0.003 & $-0.786 * * *$ \\
\hline MEF75\% & -0.339 & 0.091 & 0.405 & $-0.445 * *$ & -0.046 & -0.536 \\
\hline MEF75\% ${ }^{\#}$ & -0.307 & -0.143 & 0.619 & $-0.447 * *$ & -0.123 & -0.357 \\
\hline FEF25-75\% & $-0.413 * * *$ & 0.155 & 0.19 & $-0.493 *$ & -0.007 & $-0.786 * * *$ \\
\hline FEF25-75\%\# & -0.243 & -0.069 & 0.261 & $-0.395 * *$ & -0.006 & $-0.786 * * *$ \\
\hline $\mathrm{FEV}_{1} / \mathrm{FVC} \%$ & -0.297 & -0.357 & -0.224 & $-0.45 I^{* *}$ & -0.018 & -0.5 \\
\hline $\mathrm{FEV}_{1} / \mathrm{FVC} \%^{\#}$ & -0.229 & -0.023 & 0.048 & $-0.347 * * *$ & -0.04 & $-0.929 * *$ \\
\hline $\mathrm{FEV}_{1} / \mathrm{FVCact}$ & -0.27 & 0.189 & -0.595 & $-0.350 * * *$ & 0.019 & $-0.929 * *$ \\
\hline
\end{tabular}

\#measurement done after bronchodilator inhalation

*statistically significant correlation with $\mathrm{p}<0.00$ I

$* *$ statistically significant correlation with $\mathrm{p}<0.01$

***statistically significant correlation with $\mathrm{p}<0.05$

Table 5 Parameter changes after treatment in patients with BA, BA+COPD, COPD and CAP

\begin{tabular}{|c|c|c|c|c|c|c|}
\hline Parameter & Mild BA & Moderate BA & Severe BA & $\mathrm{BA}+\mathrm{COPD}$ & COPD & CAP \\
\hline Neutrophils & Unchanged & & & Unchanged & Unchanged & Unchanged \\
\hline NE & Unchanged & Unchanged & Unchanged & Unchanged & Unchanged & Unchanged \\
\hline AAT & Unchanged & Unchanged & Unchanged & & । & \\
\hline PAN & Unchanged & Unchanged & Unchanged & Unchanged & Unchanged & Unchanged \\
\hline Respiratory burst & Unchanged & Unchanged & Unchanged & I & Unchanged & Unchanged \\
\hline ESR & Unchanged & Unchanged & Unchanged & 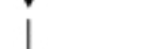 & Unchanged & \\
\hline Leukocytes & Unchanged & Unchanged & Unchanged & $\mathbf{\Delta}$ & Unchanged & Unchanged \\
\hline $\mathrm{FeNO}$ & Unchanged & 1 & Unchanged & & 1 & 1 \\
\hline
\end{tabular}

\section{Conclusion}

i. The parameters that characterize the functional status of neutrophils reflect the degree and significance of the inflammatory process in the bronchopulmonary system: the blood serum NE level was raised in patients with COPD and CAP; the AAT level was raised in patients with severe $\mathrm{BA}, \mathrm{BA}+\mathrm{COPD}, \mathrm{COPD}$ and most significantly in patients with CAP; the phagocytic activity of neutrophils was most pronounced in patients with BA irrespective of disease severity and in patients with BA+COPD.

ii. In patients with COPD, there was a statistically significant negative correlation between the sputum neutrophil percentage and $\mathrm{FEV}_{1}$, a positive correlation between the sputum neutrophil percentage and ESR, as well as a significant positive correlation between the sputum macrophage percentage and $\mathrm{FEV}_{1}$, and a negative correlation between the sputum macrophage percentage and ESR, which indicates the phases when neutrophils and macrophages participate in the inflammatory process.

iii. FeNO is a marker of both allergic (BA) and infectious (CAP) inflammation and allows the degree of inflammation in the bronchopulmonary system to be determined.

iv. The obtained correlations between the studied parameters and pulmonary function allow us to consider neutrophil, NE, AAT, PAN and respiratory burst levels as diagnostic markers of worsening bronchial passability and flow rate. 
v. The following parameters can be used to assess inflammatory changes after treatment: neutrophils in the peripheral circulation in patients with moderate and severe BA, AAT in patients with $\mathrm{BA}+\mathrm{COPD}, \mathrm{COPD}$ and $\mathrm{CAP}, \mathrm{ESR}$ in patients with $\mathrm{BA}+\mathrm{COPD}$ and $\mathrm{CAP}$, and $\mathrm{FeNO}$ in patients with moderate $\mathrm{BA}, \mathrm{BA}+\mathrm{COPD}$, COPD and CAP.

vi. Patients with $\mathrm{BA}+\mathrm{COPD}$ have infective (bacterial) inflammation demonstrated by bronchial obstruction without any clinical or laboratory signs of inflammation, bacterial and atopic sensitization as evident from the AAT levels and which was absent in patients with $\mathrm{BA}$ and patients with COPD, which allows us to view the combination of BA and COPD as a separate pathological condition.

\section{Acknowledgements}

None.

\section{Conflict of interest}

The authors do not have any conflict of interests.

\section{References}

1. MacNee W, Tuder RM. New paradigms in the pathogenesis of COPD Proc Am Thorac Soc. 2009;6(6):527-531.

2. Pinegin BV, Mayansky AN. Neutrophils: structure and function. Immunology. 2007;(6):374-382.

3. Segal AW. How neutrophils kill microbes. Annu Rev Immunol. 2005;23:197-223.

4. Gereng EA, Sukhodolo IV, Ogorodova LM, et al. The role of cellular and molecular targets in the formation of various inflammation patterns in heterogeneous phenotypes of severe bronchial asthma. Pulmonology. 2009;(5):78-82.

5. The ENFUMOSA Study Group. The ENFUMOSA cross-sectional European multicentre study of the clinical phenotype of chronic severe asthma. European Network for understanding mechanisms of severe asthma. Eur Respir J. 2003;22(3):470-477.

6. MacNee W. Oxidative stress and lung inflammation in airways disease. Eur J Pharmacol. 2001;429(1-3):195-207.

7. Averyanov AV, Polivanov AE. Deficiency of a1-antitrypsin and chronic obstructive pulmonary disease. Pulmonology. 2007;(3):103-109.

8. Agapova YR, Gulin AV. A new way of preliminary evaluation of serum antiprotease activity and humoral immunity using a proteinogram in patients with COPD, bronchial asthma, pneumonia. Bulletin of TSU. 2013;18(4):1297-1301.

9. Dolgushin II, Andreeva YS, Savochkina AY. Neutrophil traps and methods for assessing the functional status of neutrophils: monograph. Moscow: Publishing House of the Russian Academy of Medical Science; 2009: $204 \mathrm{p}$

10. Borregaard N. Neutrophils, from marrow to microbes. Immunity. 2010;33(5):657-670

11. Fitzpatrick AM, Holguin F, Teague WG, et al. Alveolar macrophage phagocytosis is impaired in children with poorly controlled ashma. $J$ Allergy Clin Immunol. 2008;121(6):1372-1378.

12. Silva-Martins CLF, Couto SC, Muniz-Junguesa MI. Inhaled corticosteroid treatment for 6 months was not sufficient to normalize phaocytosis in asthmatic children. Clin Translat Allergy. 2013;3:28.
13. Gordon SB, Read RC. Macrophage defenses against respiratory infections. Br Med Bull. 2002;61(1):45-61.

14. Fitzpatrick AM, Higgins M, Holguin F, et al. The molecular phenotype of severe asthma in children. J Allergy Clin Immunol. 2010;125(4):851-857.

15. Huynh ML, Malcolm KC, Kotaru C, et al. Defective apoptotic cell phagocytosis attenuates prostaglandin E2 and 15-hydroxyeicosatetraenoic acid in severe asthma alveolar macrophages. Am J Respir Crit Care Med. 2005;172(8):972-979.

16. Berenson CS, Garlipp MA, Grove LJ, et al. Impairen phagocytosis of nontypeable Haemophilus infuenzae by human alveolar macrophages in chronic obstructive pulmonary disease. $J$ infect Dis. 2006;194(10):1375-1384.

17. Donnely LE, Barnes PJ. Defective rhagocytosis in airways disease. Chest. 2012;141(4):1055-1062.

18. Barnes PJ. Alveolar macrophages as orchestrators of COPD. COPD. 2004;1(1):59-70.

19. Stockley RA. Neutrophils and the pathogenesis of COPD. Chest. 2002;121(5):1515-1555.

20. Berger M, Sorensen RU, Tosi MF, et al. Complement receptor expression on a neutrophils at an inflammatory site, the Pseudomonas-infected lung in cystic fibrosis. J Clin Invest. 1989;84(4):1302-1313.

21. Liang Z, Zhang Q, Thomas CM, et al. Impaired macrophage phagozytosisof bacteria in severe asthma. Respir Res. 2014;15:72.

22. Totolyan AA, Freidlin IS. Cells of the immune system. Neutrophils. SPb: Science; 2000: 231 p.

23. Sodayeva SK, Klimanov IA, Lee TV. Change in the metabolism of nitric oxide in chronic obstructive pulmonary disease in combination with chronic cerebral ischemia. Pulmonology. 2012;(1):31-34.

24. Korkmaz B, Horwitz MS, Jenne DE, et al. Neutrophil elastase? Proteinas 3 and cathepsinG as therapeutic targets in human diseases. Pharmacol Rev. 2010;62(4):726-759.

25. Iles KE, Forman HJ. Macrophage signaling and respiratory burst Immunol Res. 2002;26(1-3):95-105.

26. Drannik GN. Clinical immunology and allergology: a manual for students, interns, immunologists, allergists, physicians. Profile of all specialties; 2010: $547 \mathrm{p}$.

27. Zverev VV, Boychenko MN. Medical microbiology, virology and immunology: a textbook. Moscow: GEOTAR-Media; 2010: 445.

28. Dolgushin II, Shishkova YS, Savochkina AY. Physiological features of neutrophilic granulocytes, characteristics of neutrophilic granulocytes and methods for assessing their functional status. Germany: Lambert Publishing House; 2011: 248 p.

29. Maltseva VN, Safronova VG. Ambiguity of the role of neutrophil in the genesis of the tumor. Cytology. 2009;(6):469-474.

30. Totolyan AA. Modern approaches to diagnostics of immunopathological conditions. Totolyan Med Immunology. 2006;1(1-2):75-108.

31. Averyanov AV. Role of neutrophilic elastase in the pathogenesis of chronic obstructive pulmonary disease. Cytokines and inflammation. 2007;6(4):3-8.

32. Lee WL, Harrison RE, Grinstein S. Phagocytosis by neutrophils. Microbes Infect. 2003;5(14):1299-1306.

33. Lominadze G, Powell DW, Luerman GC, et al. Proteomic analysis of human neutrophil granules. Mol Cell Proteomics. 2005;4(10):1503-1521.

34. Shapiro SD. Neutrophil elastase: path clearer, pathogen killer, or just 
pathologic? Am J Respir Cell Mol Biol. 2002;26(3):266-268.

35. Buikin SV, VP Puzyrev. Alpha-1 antitrypsin insufficiency. Prospects for screening. Communication 1. Bulletin of the SB RAMS. 2004;1:92-97.

36. Barnes PJ, Shapiro SD, Pauwels RA. Chronic obstructive pulmonary disease: molecular and cellular mechanisms. Eur Respir J. 2003;22(4):672-688.

37. Kossodo S, Zhang J, Groves K, et al. Noninvasive in vivo quantification of neutrophil elastase activity in experimental mouse lung injury. Int $J$ Mol Imaging. 2011;581406.

38. Averyanov AV, Polivanov AE. Neutrophil elastase and diseases of the respiratory system. Pulmonology. 2006;5:74-79.

39. Fomina DS, Goryachkin LA, Nenasheva NM. Activity of neutrophilic elastase of blood serum in patients with atopic bronchial asthma. Pulmonology. 2010;2:82-86.

40. Kabanova AA, Okulich VK, Goncharova AI. Elastase activity of the oral fluid of patients with purulent-inflammatory processes of the maxillofacial region. News of Higher Educational Establishments. The Volga region. Medical sciences. 2014;30(2):68-75.

41. Paczek L, Michalska W, Bartlomiejczyk I. Trypsin, elastase, plasmin and MMP-9 activity in the serum during the human ageing process. Age Ageing. 2008;37(3):318-323.

42. Pirogov AB, Prikhodko AG, Perelman YM, et al. Cellular profile of induced sputum, the level of myeloperoxidase and neutrophilic elastase of blood in patients with bronchial asthma with airway hyperresponsiveness to the hypoosmolar stimulus. Bul fiz and pat dyh. 2015;(57):8-14.

43. Shapiro SD. Proteinases in chronic obstructive pulmonary disease Biochem Soc Trans. 2004;30(2):98-102.

44. Shchupakova AN. Proteolytic activity of neutrophil elastase as a prognostic factor in the development of diseases of the cardiovascular system. Bulletin of Vitebsk State Medical University: quarterly scientific and practical journal. 2016;15(2):17-26.

45. Innes AL, Carrington SD, Thornton DJ, et al. Ex vivo sputum analysis reveals the impairment of protease-dependent mucus degradation by plasma proteins in acute asthma. Am J Respir Crit Care Med. 2009;180(3):203-210.

46. Moir LM, Ng HY, Poniris MH, et al. Doxycycline inhibits matrix metalloproteinase-2 secretion from TSC2-null mouse embryonic fibroblasts and lymphangioleiomyomatosis cells. $\mathrm{Br} J$ Pharmacol. 2011;164(1):83-92.

47. Chalmers JD, Hill AT. Mechanisms of immune dysfunction and bacteria persistence in no-nystonic fibrosis bronchiectasis. Mol Immunol. 2013;55(1):27-34.

48. Gooptu B, Ekeowa UI, Lomas DA. Mechanisms of emphysema in alpha1-antitrypsin definity: molecular and cellular insights. Eur Respir J. 2009;34(2):475-488.

49. Srystal RG. Alpha-1 antitrypsin deficiency, emphysema and liver disease: genetic basis and strategies for therapy. $J$ Clin Invest. 1990;85(5):1343-1352.

50. Abdullaev AYu, Guliyev MR. Protease-antiprotease system components in induced sputum of patients with chronic obstructive pulmonary disease. Pulmonology. 2012;(5):33-36.

51. Fairbanks KD, Tavill AS. Liver disease in alpha 1-antitrypsin deficiency: a review. Am J Gastroenterol. 2008;103(8):2136-2141.

52. Palma-Carlos AG, Santos MAS, Palma-Carlos ML. Alfa1-antitrypsin, asthmaallergia. Asthma. 2009;10(1):27-28.
53. Ovcharenko SI, Sleep EA. Influence of a1-antitrypsin deficiency on lung lesions. Pulmonology. 2011;(5):79-86.

54. Puzyrev VP, Savyuk VYa. Molecular bases and clinical aspects of alpha1-antitrypsin insufficiency. Pulmonology. 2003;(1):105-115.

55. Lomas DA. The selective advantage of a1-antitrypsin deficiency. Am J Respir Crit Care Med. 2006;173(10):1072-1077.

56. Zhigaltsova-Kuchinskaya OA, Sivitskaya LN, Danilenko NG, et al Alpha-1-antitrypsin deficiency: genetic fundamentals, epidemiology, role in the development of bronchopulmonary pathology. Vestnik VSMU. 2015;14(6):39-52.

57. Puzyrev VP, Bubbling VP, Ogorodovoy LM, et al. Genetics of bronchopulmonary diseases: monograph. Moscow: Atmosphere, 2010; $160 \mathrm{p}$.

58. Kolesnikova EV, Alfa1-antitrypsin deficiency: a modern view of the problem. Modern gastroenterology. 2008;2:93-98.

59. Louis R, Lau LC, Bron AO, et al. The relationship between airways inflammation and asthma severity. Am J Respir Care Med. 2000;161(1):9-16.

60. Blanco IE, de Serres FJ, Fernańdez-Bustillo E, et al. alpha1-Antitrypsin and fibromyalgia: new data in favor of the inflammatory hypothesis of fibromyalgia. Medical Hypotheses. 2005;64(4):759-69.

61. Dabbagh K, Laurent GJ, Shock A, et al. Alpha-1-antitrypsin stimulates fibroblast proliferation and activates classical MAP kinase signalling pathways. J Cell Physiol. 2001;186(1):73-81.

62. Bucurenci N, Blake DR, Chidwick K, et al. Inhibition of neutrophil superoxide production by human plasma alpha 1-antitrypsin. FEBS Lett. 1992;300(1):21-24.

63. Leshenkova EV, Sobchenko SA, Kravtsov VYu. Clinico-functional, cytological and immunological characteristics of the main variants of late asthma in the stable course of the disease. Bulletin of the Russian Military Medical Academy. 2009;(3):60-64.

64. Pawar RS, Abhang SA. Evaluation of Serum Level of Neutrophil Elastase, Superoxide Dismutase and Nitric Oxide in COPD Patients and its Correlation with Lung Function Test. International Journal of Biochemistry Research. 2015;5(2):153-161.

65. Bchir S, Nasr H, Bouchet S, et al. Concomitant Elevation of MMP9, NGAL, proMMP-9 / NGAL and neutrophil elastase in serum of smokers with chronic obstructive pulmonary disease. J Cell Mol Med. 2016;20(10):1-12.

66. Scapini P, Cassatella MA. Social networking of human neutrophils within the immune system. Blood. 2014;124(5):710-719.

67. Lavinskiene S, Jeroch J, Malakauskas K, et al. Peripheral blood neutrophil activity during Dermatophagoidespteronyssinus-induced latephase airway inflammation in patients with allergic rhinitis and asthma. Inflammation. 2012;35(4):1600-1609.

68. Mosca T, Menezes MC, Silva AV, et al. Chemotactic and Phagocytic Activity of Blood Neutrophils in Allergic Asthma. Immunol Invest. 2015;44(5):509-5200.

69. Kolodkina LA. Functional activity of neutrophils in patients with chronic obstructive pulmonary disease. Problems of tuberculosis and lung diseases. 2003;(7):15-21.

70. Kokosov AN. Chronic bronchitis and obstructive pulmonary disease. SPb: Publishing house "Lan"; 2002: 288 p.

71. Garcia-Rio F, Casitas R, Romero D. Utility of two-compartment models of exhaled nitric oxide in patients with asthma. J Asthma. 2011;48(4):329-334.

Citation: Fedoseev GB, Trofimov VI, Negrutsa KV, et al. The functional status of neutrophils in patients with bronchial asthma, chronic obstructive pulmonary disease, bronchial asthma with chronic obstructive pulmonary disease, and community-acquired pneumonia.J Lung Pulm Respir Res. 20 I8;5(2):5I-63. DOI: I0.15406/jlprr.2018.05.00162 
72. Grob NM, Dweik RA. Exhaled nitric oxide in asthma. From diagnosis, to monitoring, to screening: are we there yet? Chest. 2008;133(4):837-839.

73. Schleich FN, Seidel L, Sele J, et al. Exhaled nitric oxide thresholds associated with a sputum eosinophil count $\geq 3 \%$ in a cohort of unselected patients with asthma. Thorax. 2010;65(12):1039-1044.
74. Adrie C, Monchi M, Dinh-Xuan AT, et al. Exhaled and nasal nitric oxide as a marker of pneumonia in ventilated patients. Am J Respir Crit Care Med. 2001;163(5):1143-1149.

75. Pertseva TA, Mikhaylichenko DS. Modern achievements in the diagnosis of inflammation of the respiratory tract in bronchial asthma. Asthma ta alergia. 2013;(3):61-65. 